\title{
Palabras para el cine
}

\section{Words for the Cinema}

\author{
José Manuel Mateo \\ Centro de Estudios Literarios \\ Instituto de Investigaciones Filológicas
}

\begin{abstract}
ReSUMEN: En este artículo se muestra la importancia que otorga José Revueltas a la memoria y el testimonio como elementos indispensables de la creación cinematográfica. En la primera parte de la nota se reseñan y comentan diversos aspectos de $E l$ conocimiento cinematográfico y sus problemas (1965), volumen donde se reúnen 13 escritos sobre cine que corresponden a conferencias y cursos dictados por Revueltas entre 1961 y 1965, tanto en Cuba como en México. En la segunda parte se ofrece un repertorio de 11 términos que resultan indicativos de las concepciones cinematográficas de Revueltas, pero que también pueden aprovecharse para repensar los vínculos entre literatura y cine. Esta nota es, en cierto sentido, el comienzo de una exploración encaminada a estudiar la actividad cinematográfica de un escritor que fue cinéfilo, adaptador, guionista, representante sindical, maestro, teórico y analista de cine.
\end{abstract}

ABSTRACT: This article demonstrates the emphasis that José Revueltas grants to memory and testimony as essential elements of the cinematographic creation. In the first part of the note they are outlined and discussed different aspects of the book Cinematographic knowledge and its problems (1965), volume where meet thirteen writings on cinema which correspond to lectures and courses taught by Revueltas between 1961 and 1965, both in Cuba as in Mexico. The second part provides an inventory of eleven terms that are indicative of cinematographic conceptions of Revueltas, but which can also be used for rethink the links between literature and cinema. This note is, in a sense, the beginning of an exploration aimed at studying the cinematographic activity of a writer who was a film buff, adapter, screenwriter, union representative, college professor, theoretician and film analyst.

PALABRAS ClAVE: memoria, testimonio, conciencia, método, vanguardia, José Revueltas KEYWORDS: memory, testimony, awareness, method, vanguard, José Revueltas 


\section{José Manuel Mateo}

Centro de Estudios Literarios

Instituto de Investigaciones Filológicas

\section{Palabras para el cine}

\section{Heráclito: testimonio y conciencia}

Hecha a un lado la obligación de manifestar nuestro parecer sobre la obsolescencia o la actualidad de las ideas, o bien, sobre el acierto de las valoraciones o afinidades, los planteamientos de José Revueltas sobre el arte cinematográfico impulsan a pensar, en términos amplios, cuestiones de estética y, en particular, algunos asuntos asociados con la literatura, las imágenes y la memoria. Y si estos son los primeros asuntos convocados, ello se debe a que los materiales reunidos por José Revueltas en El conocimiento cinematográfico y sus problemas (1981) dejan la impresión (la marca, la señal o la estampa) de que, sobre todo, le interesaba postular de nuevo el problema de las disposiciones y las eficacias formales, sin dejar de lado la dimensión antropológica del asunto, y aquí uso el adjetivo en su sentido disciplinario, pero también con un eco de Juan José Saer, porque la ficción literaria es, de acuerdo con el narrador argentino, una antropología especulativa (2004: 16), un modo de interesarse por el hombre que está y es visto desde una posición singular, una exploración verbal de lo humano o del mundo donde el tratamiento específico es inseparable de lo tratado.

"Sin dejar de lado", anoto, pero más bien debería expresar lo mismo de otra forma: Revueltas insiste en mostrarnos la necesaria acción de las singularidades, las relaciones y las determinaciones que articulan, 
condensan y sintetizan una obra, cuando esta no se cierra y más bien se abre a la historia y a los contenidos culturales de una época hasta conseguir que estos se sobrevivan, se superen y trasciendan su tiempo de caducidad.

En cierta forma, a Revueltas le interesa lo mismo que motivó las búsquedas de ese "padre fantasmático de la iconología" que, en palabras de Didi-Huberman, fue Abi Warburg (2013: 27); con la diferencia de que el escritor mexicano sí ponía en práctica un método de trabajo sobre "el plano de los fundamentos, como hubiesen hecho un Kant o un Hegel" (Didi-Huberman, 2013: 40), para decantar una ley general o una esencia, y Warburg procuraba "multiplicar las singularidades pertinentes" para "ampliar el campo fenoménico de una disciplina [la historia del arte] hasta entonces clavada en sus objetos... como un fetichista a sus zapatos" (Didi-Huberman, 2013: 40). José Revueltas optó por la vía clásica, sin duda, pero sus andanzas lo llevaron a observar los trasvases entre disciplinas artísticas y a establecer la obra como el sujeto de una serie de "instancias históricas heterogéneas" (Didi-Huberman, 2013: 44) que hacen de ella (de la obra), y de la actividad artística, algo abierto a otras disciplinas y a otras formas de hacer el relato de lo humano, sin que esto disipe las especificidades de la historia, la antropología, la literatura y el cine.

"El relato de lo humano"... decir que la vida humana no es abstracta parece tan obvio que no amerita comentarse, apunta Revueltas en "Lineamientos para un cine de vanguardia" (1966). No obstante, "lo que ya no resulta un lugar común es el cómo del no ser abstracto de la vida, en sus múltiples aspectos... Aquí los términos se entrelazan, se confunden, se contradicen, se combaten entre sî" (Revueltas, 1981: 139). El relato testimonial (sea verbal o icónico) no es optativo, sino necesario, cuando en verdad se desea emprender una exploración de ese cómo del no ser abstracto de la vida. Pero lo que se ve o lo que se oye, lo que se dice o se recuerda, no es en sí mismo o en su inmediatez lo no abstracto (ni el testimonio pleno), porque las realizaciones concretas o palpables presentan al ser individual abstraído de sí mismo; por ejemplo, dice Revueltas, "cuando el espectador lo tipifica en el padre de Eugenia Grandet", ve al avaro y el comerciante clásicos, pero también a un padre que ostenta cierto nombre: "en él se funden lo concreto con 
lo abstracto y, nuevamente, lo abstracto con lo concreto, en un ir y venir de extraordinarios vasos comunicantes" (1981: 139). A lo que este sencillo juego de palabras nos conduce es a considerar que "la vida se mira a sí misma en sus protagonistas, en quienes la actúan de un modo o de otro y son cada quien, desde donde sea, sus testigos mutuos - siempre ese testigo tenaz, eterno e insobornable" (1981: 139-140). Todo está al descubierto y es, precisamente por ello, necesaria una lectura que no sea pura impresión (puro efecto) de las palabras (vistas, oídas, recordadas) o una mirada que se niegue a ser un limpio en inmóvil punto de vista. El acontecimiento habrá de mirarse a sí mismo no sólo en su presente modélico sino "en su forma de ser y de haber sido y que testimonia sobre su propio yo organizado..." (1981: 140).

Revueltas habla de la película Todos somos hermanos (1965), de Óscar Menéndez, y afirma que en ella podemos reconocer "una verdadera autobiografía de la ciudad". Lo mirado por la cámara no es, entonces, el testimonio fílmico que brinda Menéndez; lo mirado es el sujeto urbano que habla a destiempo y merced a un desplazamiento de sí mismo. Revueltas sintetiza este movimiento entre lo concreto y lo abstracto, entre el testimonio y los testigos, de un modo específico que resulta indispensable contemplar: "A lo largo de su historia, en el incesante fluir del río de Heráclito, el hombre es un ser testimoniado de continuo y en trance de testimoniarse en todas las direcciones humanas posibles. He aquí pues su conciencia hacia lo pretérito o hacia el porvenir: la conciencia como su testimonio móvil y constante, eterno hasta su propio acabamiento final" (1981: 140). La conciencia es, entonces, el testimonio último, real: "De aquí el arte-testimonio; el arte-conciencia; el cineconciencia. Arte que puede ser el más puro y abstracto o el más impuro y cargado de contingencias; el más inaprehensible o menos comprometido (¿por qué no, si se dan las circunstancias?) o el más atado al acontecimiento, como en el caso de la bella película de Óscar Menéndez" (1981: 140).

Sin duda convendría exponer con amplitud lo que entiende José Revueltas por ese concepto aparentemente baldío, pero baste por ahora decir que la conciencia es un movimiento que se opone a la inercia del pensamiento, es decir, a esa actividad cognoscitiva que no cuestiona sino lo posible, que no intenta modificar sino lo modificable, un pensa- 
miento bárbaro que hace de la utilidad el vehículo encubierto donde se aloja la razón residual de toda ideología. Con esta proposición trato de abreviar varias páginas de los "Apuntes para un ensayo sobre la dialéctica de la conciencia" (1975), donde el escritor se aparta de lo que llama el pensamiento acríticamente reflexivo: ese que "lee periódicos, asiste a reuniones, hace comentarios, eleva protestas y, en suma, se politiza inadvertidamente", sin darse cuenta de que solo actúa como "negatividad limitada al perímetro de su relación causal determinante" (1982: 79), o sea, entregándose a la pura apariencia del ahora, a ese lapso cronológico que cuando se percibe ya es tiempo devenido en el que las contradicciones parecen haberse resuelto. El goce y usufructo del presente (la identidad completa del sujeto con $s u$ ahora) se vuelve así una ficción ideológica (no literaria ni artística) que subyuga y de la que tendríamos siempre y en todo momento que liberarnos mediante la poiésis, es decir, mediante una praxis que (merced a sus desplazamientos, trasposiciones y anacronismos) niega la inmediatez de "la necesidad natural, al mismo tiempo que se desvincula de sus condiciones sociales originarias y adquiere su propia naturaleza diacrónica incondicionada" (Revueltas, 1982: 79). No se trata, entonces, de ser los oportunistas que se bañan dos veces en el río de Heráclito, sino de sumergirse y disolvernos en ese río: ser el flujo y la fluencia de un testimonio incesante y en trance de realizarse en todas las direcciones humanas posibles.

Que el partido comunista se pretendiera la vanguardia proletaria es tan engañoso y fraudulento para Revueltas (y al respecto puede confrontarse el Ensayo sobre un proletariado sin cabeza, principalmente), como el gesto que asumen los escritores o cineastas cuando se autopostulan como arte de vanguardia. Arte-pop, poesía concreta "y otras mercaderías estéticas por el estilo" (1981: 138) le son repelentes porque pretendiendo ser actitudes de avanzada se retrotraen "hasta la magia" y "la Edad Media", como en el caso de la antinovela que "cada vez quiere menos Tolstoi -o, en definitiva, nada de Tolstoi-, cada vez menos Flaubert, cada vez menos Proust y que con sagrado horror mira por todas partes el abominable siglo XIX [para terminar colocándose], no más delante de Tolstoi, Flaubert o de Proust, sino más atrás”, haciendo pasar por nuevas formas medievales. Tales vanguardias no solo desembocan en el "aburrimiento, como muy bien les dijo a los partidarios 
de tal narrativa vacía Simone de Beauvoir", sino que están en riesgo de "convertirse en algo a cada momento más agresivo y que no dista tampoco de transformarse en una especie de fascismo cultural" o, por lo menos, de "furia iconoclasta" contra cualquier "tradición válida", así sea la suya propia, en caso de que los vanguardistas "acepten tener alguna" (1981: 138).

Podríamos estar completamente en desacuerdo con Revueltas, pero no se trata de eso; incluso tiene cierta razón en señalar que "toda esa quincallería" autoasumida como vanguardia "no deviene en otra cosa que en reaccionarismo puro" (1981: 138), si consideramos que en su deseo de negación a ultranza termina por escindirse de la historia; es decir: aunque lo tengan, los vanguardistas ofrecen sus obras como algo sin antecedente, haciendo de tal ausencia (pretendida) un valor, cuando en realidad su actitud perfila cierta forma de la amnesia, en tanto ignoran o rechazan su propia "riqueza humana histórica acumulada" en favor de un rendimiento estético inmediato (1982: 47). Como ocurre con los sujetos de sentidos enajenados, los artistas de vanguardia rechazan todo lo que les resulta inútil e inutilizable "y niegan toda trascendencia a cambio de la utilización efímera y condensada de su objeto, que, sin embargo, comparece ante su ojo enajenado, ante todos sus sentidos comunes y ya ininteligentes, como eternidad" (1982: 48). Son estas consideraciones, nuevamente tomadas de los "Apuntes para un ensayo sobre la dialéctica de la conciencia", las que nos sugieren el porqué del rechazo revueltiano de las vanguardias: en ellas ve "la reiteración posesiva de lo efímero, bajo formas constantemente nuevas y contenidos constantemente idénticos"; advierte allí "un ojo deshumanizado" convencido de "ver la constante de eternidad, pero esto mismo le impide advertir la propia inconstancia de su esencia, por lo que la eternidad se deshace (también artículo desechable) en la eternidad de un día, de un año, ya que no de un siglo, en las vías reales de desaparecer con la catástrofe nuclear" (1982: 48). La mención última de un cataclismo definitivo viene a cuento porque tal posibilidad o potencia humana destructiva vendría a realizar el movimiento supremo de la amnesia, la omisión accidental o voluntaria pero absoluta de la memoria entera (y la debilidad mental de la Guerra Fría vuelve hoy con el alarde mutuo de Washington y Pyongyang). 
El arte puede ser el más puro y abstracto, el más impuro y contingente, el más atado al acontecimiento e incluso el menos comprometido si se dan las circunstancias, afirma el mayor escritor comunista del siglo XX mexicano; pero bajo ningún escenario puede prescindir - entiendo- de la memoria, de una conciencia que va hacia lo pretérito o hacia el porvenir con su testimonio móvil y constante, eterno hasta su propio acabamiento final, y en lucha para que el desenlace no venga de un olvido absoluto de eso que es humano y se singulariza en los cuerpos.

Es más o menos en función de estos conceptos que el cine se vuelve para José Revueltas un modo de fluencia de las palabras, las imágenes y los gestos; una forma artística capaz de fundirnos con el río de Heráclito y al que habremos de aproximarnos enseguida a partir de una serie de categorías que el escritor y guionista de múltiples cintas dejó perfiladas en El conocimiento cinematográfico y sus problemas. Dado que esta aproximación es precisamente un apunte, solo se encuentran aquí algunas de las categorías definidas por Revueltas (ex profeso o no) para hablar del cine. Al leer estos materiales - que no niegan su condición didáctica-, asistimos, en cierto modo, a las sesiones impartidas por José Revueltas en el Instituto Cubano de Arte e Industria Cinematográfica (1961), o bien, a las conferencias dictadas en diferentes sitios de la UnAm (1962) o a los cursos en el Centro Universitario de Estudios Cinematográficos de la misma Universidad (1963 y 1965). Como los estudiantes de entonces, nos hemos dedicado a tomar nota para repensar y hacer memoria de estas palabras en futuras aproximaciones a la actividad cinematográfica de un escritor que, como recuerdan Catherine Bloch y Raúl Miranda (2015: 27), fue cinéfilo, adaptador, guionista, representante sindical [de la sección de Autores y Adaptadores del Sindicato de Trabajadores de la Producción Cinematográfica], maestro, teórico y analista de cine. Si alguien puede, entonces, brindarnos una idea de las relaciones entre el estudio de la literatura y el análisis del cine, ese es, de nuevo, José Revueltas.

\section{Para un repertorio futuro}

A continuación, se encuentran 11 términos de los muchos que José Revueltas definió como parte de los 13 escritos sobre cine que fueron 
reunidos en El conocimiento cinematográfico y sus problemas. Se disponen en orden alfabético y de cada uno se ofrece una definición que reproduce lo dicho por el autor de Los días terrenales. Toda intervención nuestra para adecuar la redacción de esta acepción inicial se encuentra entre corchetes. Cuando es posible ofrecer dos o más acepciones, cada una se separa mediante una barra simple ( I ). Por cada término se ofrece, en segundo lugar, un comentario de carácter contextual, el cual se encuentra separado de las definiciones por una doble barra ( II ). Con VERSALITAS se marcan los envíos a otros términos que forman parte de este conjunto de palabras. Los números entre paréntesis y negritas remiten a la página de El conocimiento cinematográfico y sus problemas. Cuando se hace referencia a cualquier otra obra se emplea la notación habitual: autor, año y página.

Arte. Discriminación continua de elementos inútiles [que requiere] aparte del instinto [o] la intuición [...] un método que obre como reactivo químico para mostrarnos cuál es el metal precioso y cuál la burda falsificación (33). II La necesidad del método en el arte fue planteada y defendida por Revueltas numerosas veces a partir de 1950. Para un seguimiento más o menos detallado de la cuestión puede verse "Otros muros de agua", en Lectura y libertad: Hacia una poética de José Revueltas (Mateo, 2011: 19-39). O, mejor aún, conviene remitirse a los ensayos reunidos en Cuestionamientos e intenciones (1981).

Cine. Sucesión intermitente de imágenes estáticas; [por lo tanto] síntesis dialéctica [...] de dos valores opuestos: inmovilidad-movilidad [que] hace surgir un valor nuevo dentro del cual están condensados, identificados, los contrarios: la dirección del movimiento (18). II Las dos conclusiones a las que llega Heráclito en sus principios, según apunta Alfred Fouillée (1838-1912) en su Histoire de la philosophie (1875), son los de la inestabilidad eterna y la estabilidad de esa inestabilidad misma. "O, en otras palabras, dice Revueltas, esto significa que "el equilibrio de la naturaleza es relativo y el reposo puramente apariencial" (18). Revueltas cita en español la obra de Fouillée, en su tiempo renombrado filósofo y profesor que formuló la noción de ideas-fuerza y fue autor prolífico de estudios psicológicos, trabajos históricos y métodos educativos (Boyer, 2005). 
Definición. Límite indispensable por cuanto al método del conocimiento y la necesidad de comprobar los conceptos de éste dentro de una práctica concreta, que sea precisamente la que corresponda y no ninguna otra (37). I Suma de cualidades de la cosa definida, y luego [...] aspecto particular en que se tomen dichas cualidades (38). I [Encuentro] del concepto y su aplicación (38) II Para hablar del guion cinematográfico, Revueltas comienza por tratar el problema de las definiciones y habrá de valerse del ejemplo de la sastrería para diferenciar entre un arte $\mathrm{u}$ oficio que adquiere carácter en función de sus aplicaciones diversas (sastrería de trajes militares, de vestuario teatral, etcétera) y un concepto, el guion cinematográfico, que "ya es en sí mismo" una aplicación y no necesita por ello "de una práctica que lo defina porque ya es el resultado de una práctica anterior, al grado que podría decirse que [el guion] es al cine lo que el traje a la sastrería" (38). Si el escritor desplaza su equivalencia hacia los territorios del objeto es para señalar la falta de autonomía de una forma o de un género que algunos pretenden nuevo (39); así, afirma: "el guion cinematográfico se define por su objeto: la película, y no admite ninguna otra definición ni aplicación fuera de estos límites específicos y estrictos de necesidad" (38). Véase GUION CINEMATOGRÁFICO.

Fluencia. Fluir sin tropiezos de una película [...]; uno de los principios esenciales del cine (53). II Término equivalente al de RITMO CINEMATOGRÁFICO.

Guion cinematográfico. Libreto [no dramático], obra literaria perteneciente a un género específico [que] es ya, en sí mismo, la película [...], su prefiguración (59). II Importante como fue su actividad de guionista, Revueltas se ocupa apenas de establecer una definición precisa del guion de cine; lo cual no es de lamentarse porque en "Problemas del guion cinematográfico" (37-60) se ocupa en extenso de despejar las similitudes y diferencias entre la novela y el guion, echando mano para ello del análisis literario y cinematográfico, doble procedimiento que resulta ineludible, afirma, a la hora de trasladar situaciones y materiales puramente verbales a una versión cuyo tratamiento subsiguiente depende de la cámara. Una definición alternativa, basada en los términos con los que trabaja Revueltas, sería la siguiente: forma literaria que toman las imágenes y los conceptos, destinada a la filmación de una película. 
Imagen cinematográfica. Cierto género de representación del conocimiento, no [...] diferente, en esencia, desde el punto de vista de la estética, a las imágenes de la poesía, la pintura o la novela, [pues en todas ellas] el procedimiento ordenador es el mismo; el sistema, digamos, de transustanciación de los elementos no difiere: el pan y el vino se convierten en cuerpo y sangre merced a un idéntico milagro emocional (19). II Para confirmar su afirmación, Revueltas acude a una de las canciones amorosas de Quevedo, cuyo primer verso es "Decir puede este río", y a propósito del modo en que se produce la imagen, comenta: "Quevedo ha escrito palabras, pero el encanto, la magia, la verdad en suma, radican no en las palabras dichas, sino en las escuchadas, en las que el artista no escribió pero que nuestro espíritu oye al leer sus versos. Aquí entonces, como en el cine moderno [...], una imagen nos insinúa, nos descubre otra, la imagen secreta, la imagen verdadera, la que en su literalidad no pueden darnos los vocablos" (19). Sin decirlo todavía, Revueltas prepara el camino para establecer uno de los aspectos sobre su idea del MONTAJE. Otros poemas comentados son "Campo", de Antonio Machado, y “El amor”, de Efraín Huerta.

Montaje [procedimiento y resultado]. Combinación [o] yuxtaposición de valores diferentes, que, unidos, arrojan un valor nuevo (26). I Ordenación sistemática [...] regida por leyes precisas [en las que] no cabe el axioma aritmético de que el orden de los factores no altera el producto, sino precisamente al contrario (26). I Como [procedimiento o] método [...], unión de piezas [...], de representaciones para obtener una imagen; por lo que hace a la síntesis [o resultado], piezas [...] reunidas por cuanto a su valor conceptual (31). I Combinación adecuada de representaciones [que produce] imágenes [y] combinación adecuada de imágenes [que produce] conceptos [con miras a generar] la aparición [de una] locución completa (35). II Aunque Revueltas sigue las proposiciones de Eisenstein, para fundar su comprensión cita a Rilke, quien "antes del cinematógrafo, ya encontró, por propia observación al lado de Rodin, cuáles son los principios del montaje" (25). Lo que el escultor consigue, según el poeta, es hacer del cuerpo humano un todo mediante la "acción común" de todas sus fuerzas y todos sus miembros en movimiento, así como "ordenar en un organismo" las partes de cuerpos diferentes "que se adhieren las unas a las otras por una íntima necesidad"; 
los miembros ya no pertenecen así al cuerpo del que provienen, sino que, merced al contacto, forman "una nueva cosa, una cosa que no tiene nombre y que no pertenece a nadie" (26). Precisamente eso que permanecía innominado para el poeta, es "ni más ni menos", dice Revueltas, "el resultado de un montaje" (26). Los elementos del montaje, visto el resultado como locución completa, encuentran equivalencias en los elementos y relaciones de la lengua; de ahí que el montaje tenga, según Revueltas, "su propia gramática". Los ejemplos de tales equivalencias son "numerosos", afirma nuestro autor: "la preposición puede expresarse en lo que se llama un stablishing shot [plano general]: la conjunción, en un fade out u oscurecimiento, o en una «disolvencia», o sea la fusión de dos escenas distintas" (26). El sepulturero (1926), de José Clemente Orozco, es analizado por Revueltas con detalle para establecer que el montaje no sólo es producto de la trayectoria de la vista y de la combinación de elementos concretos sino de una "función dramática" (32).

Movimiento. Uno de los elementos constitutivos de la síntesis que realiza el arte al condensar, en una sola unidad, el tiempo y el espacio (22). I Fenómeno emocional intelectivo (27). II El movimiento en una imagen poética, plástica o cinematográfica no está definido por la trayectoria de la vista ni por la disposición de planos para sugerir un trayecto concreto; esto quiere decir que "los horizontes, las perspectivas, las profundidades, los volúmenes, los planos y una adecuada «trayectoria de la vista»" puede hacer de la pintura, de la fotografía o del filme algo "más o menos en movimiento", pero nada más (24); el elemento constitutivo al que se refiere Revueltas corresponde más bien a la "exposición coordinada y orgánica de tema, contenido, trama y acción”, así como a la "combinación o yuxtaposición e interpenetración de valores diversos, a efecto de obtener un todo armónico" (25). El escritor sigue en parte lo expuesto por Eisenstein en su libro El sentido del cine, pero añade elementos que lo alejan del cineasta ruso; retoma los ejemplos que ofrece el director (el Encuentro de San Antonio y San Pablo, de Sassetta, junto con La adoración de los pastores, de Doménico Ghirladino), pero aporta los propios: varios relativos a la poesía (v. IMAGEN CINEMATOGRÁFICA), en otros casos acude a los muralistas (en especial a Orozco) y muy marcadamente a una obra de Manuel Álvarez Bravo: Un poco alegre y graciosa. La valoración general que hace del fotógra- 
fo se basa en el parecer de Villaurrutia; dice Revueltas: Álvarez Bravo "tiene ese atributo que define y califica al arte: el de prescindir, el de despojarse de todo lo accesorio para ofrecer el signo puro, la ecuación lírica precisa, la síntesis heroica y acabada" (24). El movimiento de una obra sería, así, la síntesis lograda mediante el desprendimiento de todo elemento emocional e intelectivo que no contribuye a perfilar el destino de la ecuación estética.

Ritmo cinematográfico. Fluencia de una obra cinematográfica [ausencia de saltos en la locución formada por el montaje; v. FLUENCIA] (36). II A pesar de la importancia que otorga Revueltas al ritmo de una película, no se detiene sino brevemente en su definición; en cambio, ofrece razones para no hacer "un traslado excesivamente mecánico de la acepción que en música tiene la palabra” (35). En música, afirma, "el ritmo significa más o menos la proporción que se guarda entre el tiempo de un movimiento y el de otro diferente [...]. La relación que hay entre un allegro o un scherzo, digamos, es una relación de tempo, aparte su estructura, por lo que entonces el tiempo representa para el ritmo musical un principio básico e imprescindible. En el cine ocurre de modo diferente. Si bien es cierto que el ritmo cinematográfico no puede prescindir del tiempo - movimiento de los personajes y duración de las tomas - no está en modo alguno determinado por él; en cambio el movimiento de los personajes y la duración de las tomas sí están determinadas por el ritmo a la vez que por el tema, la trama y el contenido de la obra" (35). "El ritmo representa ese sentido mágico que permite al artista inventar sus materiales antes de comenzar la realización de la obra y tener esos materiales dispuestos para que desempeñen su cometido en la concepción general, en el gran todo armónico que se ha propuesto. El ritmo ha sido creado por los dioses" (36). Con semejante afirmación final, el escritor confirma, de modo inequívoco, la condición precedente del ritmo en la concepción cinematográfica: si la película fluye sin distracciones, desvíos o sobresaltos ajenos al concepto ("basta una representación o una imagen falsas para que la película «brinque», como se dice en el argot cinematográfico") es porque se ha seguido de antemano ese "principio ordenador donde radica la fuerza creadora del cine" (36). Al respecto véase también ARTE. 
Tiempo cinematográfico. Lentitud o rapidez de la acción, brevedad o extensión de las tomas (35). II En cine, el tiempo no determina el ritmo de la película sino a la inversa, porque no se trata del "tiempo real, cuyo minuto se divide en sesenta segundos", sino del "tiempo interno donde radica el ritmo [o] la fluencia de una película" (53). El tiempo fílmico obedece así a un ritmo prefigurado por el artista (véase RITMO CINEMATOGRÁFICO).

Timing [anglicismo]. Relación de tiempo correspondiente... entre una toma y otra, entre una secuencia y otra (53). II Si seguimos lo dicho por Revueltas a propósito del RITMO, el timing sería equivalente a lo que se entiende por tempo en música, y contribuye, entonces, a establecer el ritmo de la película, pero no es su equivalente. Puede diferenciarse en la práctica entre timing, tiempo cinematográfico y ritmo si se siguen los análisis literario y cinematográfico con los cuales Revueltas elabora un guion de los primeros tres párrafos de La mujer adúltera, de Albert Camus, en "Problemas del guión cinematográfico" (37-60).

Unidad. Atributo definidor de la belleza [que] debe tomarse en su acepción antónima, esto es, como síntesis monística de entidades adversas entre sí, como condensación unitaria que hace interpenetrarse los valores opuestos y reduce las categorías contrarias a lo uno (18). II Revueltas establece su concepto de unidad siguiendo la "«revelación» dialéctica" que tuvo san Agustín cuando este ofreció su concepto de la poesía: "consiste en la unidad, como todo lo bello"; al mismo tiempo se pregunta si tal idea no surgió al acercarse el obispo de Hipona hacia el río de Heráclito "para beber en las refrescantes aguas de la identidad de los contrarios" (17 y 18).

\section{Bibliografía}

BOyer, Pierre-Xavier (2005). "Aux origines de l'élitisme républicain: Les aristocraties d'Alfred Fouillée", Revue Française d'Histoire des Idées Politiques, 2005/2, núm. 22: 37-49. <https://www.cairn.info/revue-francaise-d-histoire-des-ideespolitiques 1-2005-2-page-37.htm>, consultado por última vez el 23 de enero de 2018.

Bloch, Catherine y Raúl Miranda Peredo (2015). "José Revueltas: un rebelde en el cine mexicano", en Francisco Peredo y Carlos Narro (coords). 
José Revueltas. Obra cinematográfica (1943-1976). México, Universidad Nacional Autónoma de México: 27-44.

DiDI-HuBERMAN, Georges (2013). La imagen superviviente. Historia del arte y tiempo de los fantasmas según Aby Warburg. Traducción de Juan Calatrava. Madrid, Abada Editores.

Fouillée, Alfred (1882). Histoire de la philosophie, $13^{\mathrm{a}}$ ed., París, Librairie Ch. Delagrave, <http://gallica.bnf.fr/ark:/12148/bpt6k86308709>, consultado por última vez el 23 de enero de 2018.

Mateo, José Manuel (2011). "Otros muros de agua", en Lectura y libertad: Hacia una poética de José Revueltas. México, El Colegio de San Luis: 19-39.

RevUeltas, José (1981). El conocimiento cinematográfico y sus problemas [obras completas, 22]. Prólogo de Emilio García Riera, recopilación y notas de Andrea Revueltas y Philippe Cheron. México, Ediciones Era.

Revueltas, José (1981a). Cuestionamientos e intenciones [obras completas, 18]. $2^{\mathrm{a}}$ ed., presentación, recopilación y notas de Andrea Revueltas y Philippe Cheron. México, Ediciones Era.

Revueltas, José (1982). "Apuntes para un ensayo sobre la dialéctica de la conciencia”, en Dialéctica de la conciencia [obras completas, 20]. Prólogo de Henri Lefebvre, recopilación y notas de Andrea Revueltas y Philippe Cheron. México, Ediciones Era: 17-82.

SAER, Juan José (2004). "El concepto de ficción", en El concepto de ficción. Buenos Aires, Seix Barral: 9-16. 